\title{
The Effect of Sildenafil on Recuperation from Sciatic Nerve Injury in Rats
}

\author{
Mehmet Fatih Korkmaz ${ }^{1}$, Hakan Parlakpınar ${ }^{2}$, Mehmet Fethi Ceylan $^{1}$, Levent Ediz ${ }^{3}$, Emine Şamdanci ${ }^{4}$, \\ Ersoy Kekillí, Mustafa Sağır²
}

\author{
${ }^{1}$ Department of Orthopaedics and Traumatology, İnönü University School of Medicine, Malatya, Turkey \\ ${ }^{2}$ Department of Pharmacology, İnönü University School of Medicine, Malatya, Turkey \\ ${ }^{3}$ Department of Physical Therapy and Rehabilitation, Van Yüzüncü Yıl University School of Medicine, Van, Turkey \\ ${ }^{4}$ Department of Pathology, İnönü University School of Medicine, Malatya, Turkey \\ ${ }^{5}$ Department of Nuclear Medicine, İnönü University School of Medicine, Malatya, Turkey
}

Background: Severe functional and anatomical defects can be detected after the peripheral nerve injury. Pharmacological approaches are preferred rather than surgical treatment in the treatment of nerve injuries.

Aims: The aim of this study is to perform histopathological, functional and bone densitometry examinations of the effects of sildenafil on nerve regeneration in a rat model of peripheral nerve crush injury.

Study Design: Animal experiment.

Methods: The study included a total of thirty adult Sprague-Dawley rats that were divided into three groups of ten rats each. In all rats, a crush injury was created by clamping the right sciatic nerve for one minute. One day before the procedure, rats in group 1 were started on a 28-day treatment consisting of a daily dose of $20 \mathrm{mg} / \mathrm{kg}$ body weight sildenafil citrate given orally via a nasogastric tube, while the rats in group 2 were started on an every-other-day dose of 10 $\mathrm{mg} / \mathrm{kg}$ body weight sildenafil citrate. Rats from group 3 were not administered any drugs. Forty-two days after the nerve damage was created, functional and histopathological examination of both sciatic nerves and bone densitometric evaluation of the extremities were conducted.
Results: During the rotarod test, rats from group 3 spent the least amount of time on the rod compared to the drug treatment groups at speeds of $20 \mathrm{rpm}, 30 \mathrm{rpm}$ and $40 \mathrm{rpm}$. In addition, the duration for which each animal could stay on the rod throughout the accelerod test significantly reduced in rats from group 3 compared to rats from groups 1 and 2 in the 4-min test. For the hot-plate latency time, there were no differences among the groups in either the basal level or after sciatic nerve injury. Moreover, there was no significant difference between the groups in terms of the static sciatic index (SSI) on the $42^{\text {nd }}$ day $(\mathrm{p}=0.147)$. The amplitude was better evaluated in group 1 compared to the other two groups $(\mathrm{p}<0.05)$. Under microscopic evaluation, we observed the greatest amount of nerve regeneration in group 1 and the lowest in group 3. However, this difference was not statistically significant. Moreover, there was no significant difference in the bone mineral density (BMD) levels among the groups.

Conclusion: We believe that a daily single dose of sildenafil plays an important role in the treatment of sciatic nerve damage and bone healing and thus can be used as supportive clinical treatment.

Keywords: Bone density, peripheral nerve injuries, rotarod test, sildenafil, sciatic nerve

This study was presented as a poster at the Combined Congress of $12^{\text {th }}$ HKIOF, $10^{\text {th }}$ APSS \& APPOS, 5-7 June 2015, Hong Kong, China and Bone and Joint Congress, 22-26 April 2015, Antalya, Turkey.

Address for Correspondence: Dr. Mehmet Fatih Korkmaz, Department of Orthopaedics and Traumatology, İnönü University School of Medicine, Malatya, Turkey Phone: +90 5055566777 e-mail: fatih.korkmaz@inonu.edu.tr

Received: 14 August $2014 \quad$ Accepted: 1 September $2015 \cdot$ DOI: 10.5152/balkanmedj.2016.14701

Available at www.balkanmedicaljournal.org

Cite this article as:

Korkmaz MF, Parlakpınar H, Ceylan MF, Ediz L, Şamdancı E, Kekilli E, et al. The effect of sildenafil on recuperation from sciatic nerve injury in rats.

Balkan Med J 2016;33:204-11 
Peripheral nerve damage can develop due to congenital, mechanical, thermal, chemical and other causes. If the nerve damage is not repaired in a timely manner and using proper techniques, it may lead to loss of sensation and muscle function and can also cause painful neuropathy (1). Currently, there is no established method for the treatment of peripheral nerve damage (2).

Nowadays, non-steroidal anti-inflammatory agents, steroids, nerve growth factors, erythropoietin, thyroid hormone, growth hormone, adrenocorticotropic hormone and insulinlike peptides are used in the treatment of experimentally-induced peripheral nerve damage (3-6).

Sildenafil is a selective inhibitor of phosphodiesterase- 5 (PDE-5), which catalyzes the degradation of cGMP, a primary factor in vascular smooth muscle relaxation. Intravenous or oral administration of sildenafil leads to a significant reduction in the size of an infarct caused by myocardial ischemia/ reperfusion injury. Sildenafil-induced cardiac protection has been reported in mouse and rat global ischemia and reperfusion models $(7,8)$.

In addition, sildenafil citrate has been reported to reduce flap necrosis in preclinical animal models by increasing the secretion of growth factors (FGF and VEGF) (9). A study of a rat cavernous nerve $(\mathrm{CN})$ crush injury model showed that sildenafil-treated animals differed histologically in $\mathrm{CN}$ architecture compared to untreated animals, but it was not discussed whether these changes represented a new neuroregenerative effect (10).

In this study, we aimed to perform histopathological, functional and bone densitometry examinations of the properties of sildenafil on nerve regeneration of peripheral nerve crush injury in a rat model.

\section{MATERIALS AND METHODS}

Animals
Thirty male Sprague-Dawley rats weighing between 210
and $240 \mathrm{~g}$ were obtained from the University Laboratory Ani-
mals Research Center. The rats were housed in plastic cages
and room temperature was set up $21 \pm 2^{\circ} \mathrm{C}$ and humidity of
$60 \pm 5 \%$ under a 12 -hour light/dark cycle. The experiments
were performed according to the standards of animal research
institute (Reference Number: $2012 / \mathrm{A} 71$ ).

\section{Experimental design}

Our study included a total of 30 adult Sprague-Dawley rats that were distributed into three groups so that each group consisted of ten rats. Rats from all groups were anesthetized with xylazine + ketamine and then a crush injury was created by us- ing a one-minute long vascular clamp to the right sciatic nerve. One day before the procedure, rats from Group 1 were started on a 28-day treatment consisting of a daily dose of $20 \mathrm{mg} / \mathrm{kg}$ body weight sildenafil given orally via nasogastric tube, while the rats from Group 2 were started on an every-other-day dose of $10 \mathrm{mg} / \mathrm{kg}$ body weight sildenafil citrate. Rats from Group 3 did not receive any drugs. Subjects in all 3 groups were fed ad libitum with normal rat chow and tap water. Forty-two days after the nerve damage was created, the rats underwent a static sciatic index (SSI) test, sedation and motor coordination tests, and accelerated rotarod tests. Rats were sacrificed under anesthesia and their sciatic nerves were removed surgically. Histopathologic analyses of the nerves and bone densitometry evaluation of the extremities were then performed.

\section{Measurement of sedation and motor coordination}

Before testing, the animals first needed to be trained for the task. Each animal was placed on the rod at the lowest rod speed $(5 \mathrm{rpm})$ and then taken off the rod several times. Training was complete when the animals stepped voluntarily from the investigator's hand onto the rotating rod without assistance; this indicated that the rats were acclimated to both the task and to being handled by the investigator and were not stressed. In addition, once the training was complete, the rats remained on the rod when it had stopped moving until the researcher removed them.

\section{Rotarod and the accelerod tests}

A Rotamex 4/8 system (Columbus Instruments; OH, USA) apparatus was used for the tests. The rod $(3 \mathrm{~cm}$ diameter and $40 \mathrm{~cm}$ long) was subdivided into four equal compartments. Trials were done to choose the test groups at 24 hours prior to the experiments. Animals that were able to remain on the rod in two successive trials were chosen for drug testing. The results were indicated as the percentage of rats that succeeded in remaining on the rod until the cut-off time $(300 \mathrm{sec})$ had been reached. Total running time on the rotarod, as well as the time to the fall and all set-up parameters was recorded. The rats were established on a rotating rod and tested at varied rotation speeds (maximum 5 minutes), beginning at the minimum speed $(5 \mathrm{rpm})$ and increasing in a progressive manner to $40 \mathrm{rpm}$ at $10 \mathrm{rpm}$ increments allowing quantification of the duration of each rat's ability to stay on the rod at a given rotational velocity. The accelerod test was set up with accelerations within 4 and $10 \mathrm{~min}$ from 1 to $79 \mathrm{rpm}$. Since a number of animals were generally tested during the same session, all rats were allowed to rest for about 5 minutes between the discrepant velocity tests (11). All tests were started at about the same time between $09.00-17.00 \mathrm{~h}$ and the lights were turned off. 


\section{Static sciatic index}

The SSI test was performed to evaluate the animals' sciatic nerve injury and repair (12). On the $42^{\text {nd }}$ day after nerve injury, both feet of the rats were stained black and their footprints were taken on white paper in the course which was $8 \times 80 \mathrm{~cm}$ in size. The mean of at least 3 measurable footprints was obtained from each rat. The foot width (FW) was the distance between $1^{\text {st }}$ and $5^{\text {th }}$ fingers while the mean foot width (MFW) was the distance between $2^{\text {nd }}$ and $4^{\text {th }}$ fingers. By using these values, the foot width function (FWF) and the mean foot width function (MFWF) were calculated by the formulas of FWF: EFW-NFW/NFW and MFWF: EMFW-NMFW/NMFW, respectively.

EFW: experimental foot width (right), NFW: non-operated foot width (left), EMFW: experimental mean foot width, NMFW: non-operated foot width.

The index of the sciatic nerve was calculated for each rat by the Formula below:

ISN: 108.44 FWF + 31.85 MFWF - 5.49

The index of sciatic nerve has been accepted as zero while it has been accepted -100 when there was a total injury in the sciatic nerve.

\section{Analgesia measurement}

Acute thermal pain was estimated by the hot plate test, which is an established method for measuring thermal analgesia in rodents.

\section{Hot plate test}

The hot plate (Columbus Instruments; OH, USA) surface was heated to provide a fixed temperature of $50 \pm 0.5^{\circ} \mathrm{C}$, which was verified by digital thermometer. The time between the placement of the animals on the plate and the onset of paw licking, jumping off the plate and shaking were noted as the response latency. To beware of animal injury, the cut-off time was accepted as 60 seconds (13).

\section{Measurement of Bone Mineral Density (BMD)}

Bone mineral density was calculated using dual energy Xray absorptiometry (HologicQDR-4500, Hologic Inc.; Bedford, USA) and sub-region analysis software in the bilateral femoral diaphysis. Rectangular (5x15 pixel) regions of interest were placed on the diaphysis of bilateral femurs. BMD was obtained as $\mathrm{g} / \mathrm{cm}^{2}$ and statistically compared.

\section{Histopathological evaluation}

After the decapitation of rats, sciatic nerve specimens were placed in $10 \%$ neutral buffered formalin solution. The proximal area of the sciatic nerve was stained with red tissuemarking dye, whereas the distal area of the sciatic nerve was stained with green tissue-marking dye. Tissue samples were then processed routinely by embedding in paraffin. Half of the sciatic samples were embedded in paraffin horizontally, while the other half of the sciatic samples were embedded transversally. Five micrometer thick sections were cut, deparaffinized, hydrated, and stained with hematoxylin and eosin (H\&E). The sections were stained with luksol fast blue (LFB) and phosphotungstic acid hematoxylin (PTAH) to determine myelin sheath structure. All areas of each sciatic section that had been obtained from all groups and all three dye-stained sections were examined in a blinded fashion and scored as present or absent for inflammation, myelin degeneration, and vacuolization. The sections were examined using an Olympus BX-53 research light microscope.

\section{Statistical analysis}

A computer program (SPSS Statistics for Windows, Version 22.0. IBM Corp. 2013; Armonk, NY) was used for statistical analysis. In the current study for detecting even minor effects, the animal numbers necessary for a power of 0.80 were calculated by NCSS software (Kaysville, UT). The normality of the distribution was verified by the Kolmogorov-Smirnov test. According to the results of the normality test, Kruskal-Wallis $\mathrm{H}$ and one-way analysis of variance (ANOVA) tests were used for the statistical analysis. Multiple comparisons were conducted using Tukey's test (for homogeneous variances) after the ANOVA test. The results are expressed as mean \pm standard deviation (SD) for bone mineral density levels (Table 4). For the other results (Table 1-3), the Conover test was also performed after a significant Kruskal-Wallis $\mathrm{H}$ test. P values less than 0.05 were accepted as statistically significant. The results are expressed as mean \pm standard deviation (SD) for bone mineral density levels. For the other results, the Conover test was also performed after a significant Kruskal-Wallis $\mathrm{H}$ test. P values less than 0.05 were accepted as statistically significant. The results are expressed as median (min-max).

\section{RESULTS}

Comparison of mean values of body weight did not show a statistically significant difference between groups $(p>0.05)$. In the basal performance of rotarod and accelerod results, there were no differences between the groups. The rats from group 3 (sciatic nerve injured with no drug treatment) had less time on the rod compared to the drug treatment groups at $20 \mathrm{rpm}$, $30 \mathrm{rpm}$ and $40 \mathrm{rpm}$ during the rotarod test (Table 1, $<<0.05$ ). Moreover, the duration that each animal could stay on the rod throughout the accelerod test was significantly reduced in the group 3 animals when compared groups 1 and 2 in the 4-min test (Table $1, \mathrm{p}<0.05$ ). 
For the hot plate latency time, there were no differences among the groups in either basal level or after sciatic nerve injury (Table 2, p>0.05).

\section{The static sciatic index (Walking-track analysis)}

At the sixth week, SSI values in all groups were similar to each other. There were no significant differences between the groups (Table 3, $\mathrm{p}>0.05$ ).

\section{Measurement of BMD}

There was no significant difference in the bone mineral density levels among groups (Table 4). Meanwhile, within the groups, 42 days after sciatic nerve injury, the BMD of the injured femoral diaphysis were significantly reduced by $3.6 \%$, $7.5 \%$ and $11.5 \%$ in groups 1,2 and 3 , respectively.

\section{Histopathological evaluation}

The results of histopathological observations are summarized in Table 5. Briefly, there was Wallerian-type degenera-

TABLE 1. Rotarod and accelerod results

\begin{tabular}{lccc}
\hline Variable & $\begin{array}{c}\text { Group 1 } \\
(\mathrm{n}=10)\end{array}$ & $\begin{array}{c}\text { Group 2 } \\
(\mathrm{n}=10)\end{array}$ & $\begin{array}{c}\text { Group 3 } \\
(\mathrm{n}=10)\end{array}$ \\
\hline Baseline Rotarod test (sec) & & & \\
$5 \mathrm{rpm}$ & $300(290-300)$ & $300(272-300)$ & $300(260-300)$ \\
$10 \mathrm{rpm}$ & $300(261-300)$ & $300(232-300)$ & $300(279-300)$ \\
$20 \mathrm{rpm}$ & $195(146-240)$ & $151(124-281)$ & $205(120-300)$ \\
$30 \mathrm{rpm}$ & $48(17-151)$ & $71(40-150)$ & $52(20-130)$ \\
$40 \mathrm{rpm}$ & $14(5-50)$ & $5(5-35)$ & $7(5-58)$ \\
Rotarod test after SNI (sec) & & \\
$5 \mathrm{rpm}$ & $300(290-300)$ & $300(250-300)$ & $300(290-300)$ \\
$10 \mathrm{rpm}$ & $120(82-300)$ & $168(58-300)$ & $130(40-300)$ \\
$20 \mathrm{rpm}$ & $80(63-300)$ & $91(72-300)$ & $40(16-63)^{*}$ \\
$30 \mathrm{rpm}$ & $70(50-300)$ & $72(57-300)$ & $16(10-28)^{*}$ \\
$40 \mathrm{rpm}$ & $41(15-120)$ & $42(20-110)$ & $12(10-25)^{*}$ \\
\hline
\end{tabular}

SNI: sciatic nerve injury

TABLE 2. Hot-plate latency time results (sec)

\begin{tabular}{lccc}
\hline Variable (min) & $\begin{array}{c}\text { Group 1 } \\
(\mathrm{n}=10)\end{array}$ & $\begin{array}{c}\text { Group 2 } \\
(\mathrm{n}=10)\end{array}$ & $\begin{array}{c}\text { Group 3 } \\
(\mathrm{n}=10)\end{array}$ \\
\hline Basal & $20(18-22)$ & $20(16-25)$ & $20(11-23)$ \\
After SNI & $16(13-22)$ & $17(12-22)$ & $20(15-23)$ \\
\hline
\end{tabular}

Data were presented as median (min-max).

SNI: sciatic nerve injury

TABLE 3. The results of the static sciatic index (SSI) for each group. The data are presented as median (min-max).

\begin{tabular}{lcc}
\hline Group $1(\mathrm{n}=10)$ & Group 2 $(\mathrm{n}=10)$ & Group $3(\mathrm{n}=10)$ \\
\hline $4.94(-21.67-25.28)$ & $-3.39(-21.10-9.83)$ & $-0.49(-17.47-13.60)$ \\
\hline
\end{tabular}

tion characterized by a swollen myelin sheath and limited sizes of digestion chambers accompanied by few gitter cells were recognizable in Group 3 (Figure 1). The degree of degeneration was ameliorated in both treatment groups (Figure 2), although no difference was recognized between the treatment groups. No inflammatory cellular infiltration was observed in any of the groups studied.

\section{DISCUSSION}

Crush or tension nerve injuries are typically more common than cut or rupture injuries in extremity surgeries. Orthopedic surgeons also come across such injuries during the treatment of long bone fractures and sometimes after surgeries as well. Issues such as remyelination and demyelination, axonal regeneration and degeneration, focal, multifocal, or diffuse loss of nerve fiber and endoneural edema may be encountered in crush injuries (14-16).

Severe functional and anatomical defects can be detected after peripheral nerve injury. The increase in the incidence of such injuries is in line with the development of technology in industrialized societies. Spontaneous regeneration in the distal nerve area after peripheral nerve injuries can provide good functional return $(17,18)$. Pharmacological rather than surgical treatment is preferred in the treatment of nerve injuries. Various pharmacological agents have been reported to be experimentally successful in this regard (19-24).

Sildenafil is a potent PDE-5 inhibitor. Sildenafil-induced cardiac protection has been reported in global ischemia and reperfusion mouse and rat models $(7,8)$. In addition, sildenafil citrate has been reported to decrease flap necrosis in preclinical animal models by increasing the secretion of growth fac-

TABLE 4. Bone mineral density levels of all groups

\begin{tabular}{lcccc}
\hline Group & $\mathrm{N}$ & $\begin{array}{c}\text { BMD of } \\
\text { Right Femoral } \\
\text { Diaphysis }\end{array}$ & $\begin{array}{c}\text { BMD of } \\
\text { Left Femoral } \\
\text { Diaphysis }\end{array}$ & $\mathrm{p}$ \\
\hline Group 1 & 10 & $0.237 \pm 0.04$ & $0.258 \pm 0.03$ & 0.008 \\
Group 2 & 10 & $0.211 \pm 0.04$ & $0.228 \pm 0.04$ & 0.007 \\
Group 3 & 10 & $0.170 \pm 0.02^{*}$ & $0.192 \pm 0.02$ & 0.005 \\
\hline BMD: bone mineral density; N: number & \\
\multicolumn{5}{c}{ TABLE 5. Histopathological findings of the sciatic nerves } \\
\hline Groups & Inflammatory cellular & Wallerian \\
& infiltration & degeneration \\
\hline Group 1 & No & Moderate \\
Group 2 & No & Moderate \\
Group 3 & No & Severe \\
\hline
\end{tabular}



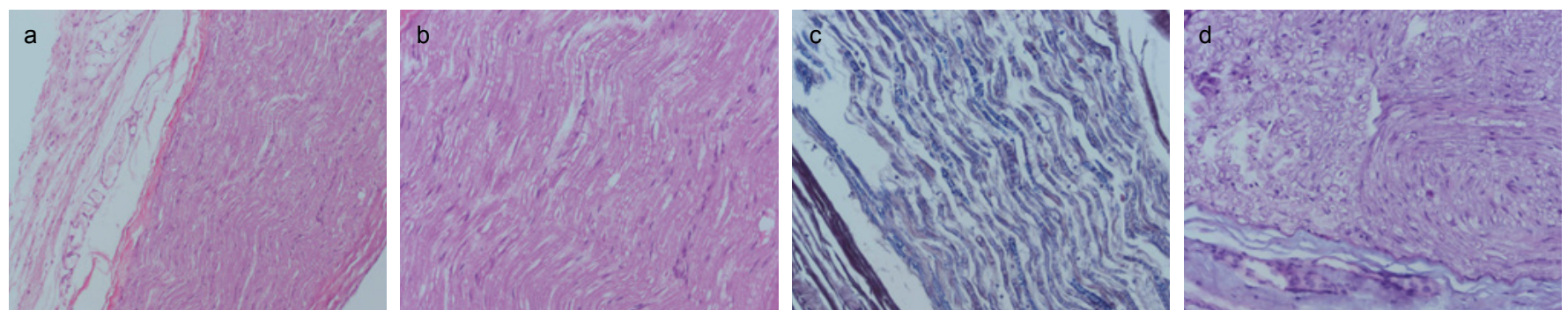

FIG. 1. a-d. The edema of nerve sheath (Group C), H\&E X100 (a), the degeneration and severe vacuolization of nerve sheath (Group C), H\&E X200 (b), the loss of myelin in degenerated nerve sheath (pale area) (Group C), PTAH X200 (c), the loss of myelin in degenerated nerve sheath (pale area) (Group C), LFB X200 (d).
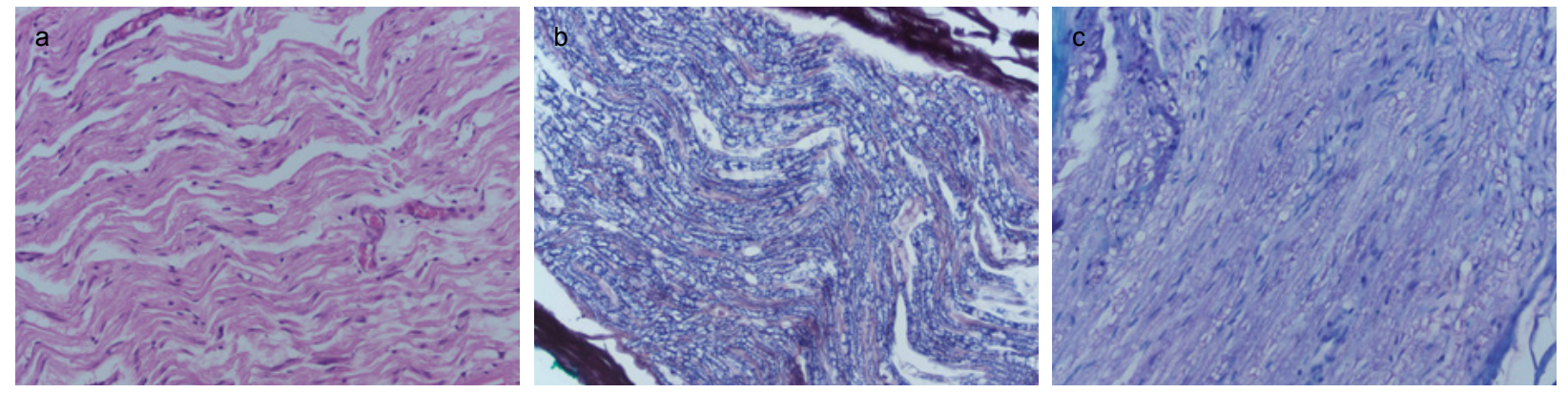

FIG. 2. a-c. Decreased vacuolization of nerve fiber (Groups A and B), H\&E X200, (a), the vacuolization of nerve fiber with decreased myelin (Groups A and B), PTAH X200 (b), the vacuolization of nerve fiber with decreased myelin (Groups A and B), LFB X200 (c).

tors (FGF and VEGF), and histologically was shown to be effective in rat cavernous nerve architecture $(9,10)$.

Accordingly, in the current study, sedation and motor impairment parameters were assessed using the rotarod and accelerod tests prior to the hot plate test. The main findings of the rotarod-accelerod tests were that the sciatic nerve-injured rats exerted a reduced length of the motor coordination performance compared to the drug treatment groups. However, the difference in recovery time from motor-coordination impairment was not found to be significant between the two drug therapy applications.

The electrophysiological, morphological and histological procedures that are used for assessment of experimental peripheral nerve regeneration are not sufficiently decisive to determine nerve healing (14-16,25,26). Baptista et al. (12) reported that walking track analysis should be performed for functional assessment of the sciatic nerve in rats. Later, this method was changed and named SSI. It has been seen that, after sciatic nerve injury, the SSI score gradually increases and reaches normal values after seven weeks. Similarly, other studies have also shown that just one month after the crush injury, subjects were able to walk normally $(27,28)$. The difference in the recovery of motor rate function might be related to various pathophysiological responses to different peripheral nerve crushes (29).
In our study, the SSI value at six weeks was significantly higher in group 1 when compared to the other groups, which might be an indication of the accelerating effect of sildenafil on recovery after nerve crush injury.

After trauma is exerted on the nerves, changes occur on both sides of the lesion. It has been reported that edema develops in the distal part of the axon and then the nerve damage spreads, starting from the injury site toward the distal end of the nerve. Next, chromatolysis develops in the body of the nerve cell and in parallel to that many histological changes such as edema are observed as well (30).

Sunderland second-degree injury or axonotmesis is characterized by axonal damage, Wallerian degeneration of the distal nerve, and continuing integrity of the endoneurial sheath. Spontaneous regeneration at the distal nerve after such injury can provide a good functional return $(17,18)$.

Peripheral nervous system regeneration, although effective, might not always result in full functional recovery. During the functional recovery of the nerve, regenerating axons must reach a distant target. Axonal regeneration is 2-3.5 mm day (31). Galtrey and Fawcett (31) have reported the onset of recovery at 14 to 56 days and functional recovery at 21-42 days. In full functional recovery, first the axon diameter and myelin sheath thickness should return to normal values. After trauma, despite axonal damage, if Schwann cells, basal lamina and perineurium are intact, then renewal would be easier (30). 
Following the peripheral nerve trauma, collagen and other connective tissue components were observed as increased, especially in the epineurium $(32,33)$. In brief, myelin degeneration, edema, and vacuolization occurred in Group 3. Sciatic nerve damage was ameliorated in both treatment groups. However, there was no difference between the treatment groups.

Yang et al. (34) reported that sildenafil enhances standard bone morphogenetic protein signaling through c-GMP and cGMP-dependent protein kinase I in vivo and in vitro. Yaman et al. (35) reported that, in rats, sildenafil could be used as a supporting factor to accelerate the healing process of defective bone in oral and maxillofacial surgeries. Histing et al. (36) determined whether sildenafil also influenced bone formation along the fracture amelioration in a femur fracture model with murine closed. Two weeks after the fracture recovery, sildenafil treatment significantly ameliorated osseous fracture bridging and smaller callus, indicating an accelerated healing process. Sun et al. (37) reported that distal femoral and proximal tibial BMD were reduced by $25 \%$ and $16 \%$, respectively, in rats with spinal cord injury at 56 days. Jiang et al. (38) reported that bone loss was $11.5 \%$ using dual-energy $\mathrm{X}$-ray absorptiometry in rats with spinal cord injury on day 21. In another dual-energy X-ray absorptiometry study, bone loss was reported to be $8.4 \%$ in rats with chronic constriction injury (CCI) of the sciatic nerve at the fifth week (39). Cardozo et al. (40) investigated whether nandrolone has protective effects against loss and slow muscle atrophy after nerve transection. They reported that reductions in BMD for femur and tibia were $7 \%$ and $12 \%$ on the $28^{\text {th }}$ and $56^{\text {th }}$ days, respectively. In our study, the BMD of the injured femoral diaphysis was significantly reduced 42 days after sciatic nerve injuries in all groups $(\mathrm{p}=0.005)$. In addition, in our study, the BMD decrease rate in the group that was administered a daily dose of sildenafil every day of the week was $3.6 \%$, in the group that received sildenafil three times a week it was $7.5 \%$ and in the group that did not receive any medication it was $11.5 \%$.

One of our important limitations is the deficiency of electromyographic analysis. Because of the limited facilities, we only evaluated histopathological, functional (rotarod-accelerorod, hot-plate tests and SSI) and bone densitometry examinations of the protective effects of sildenafil on sciatic-nerve regeneration in an animal model of peripheral nerve crush damage. A strength of the current study is that according to our results, sildenafil treatment exerts significant amelioration in the motor coordination performance and histopathological findings. As this is the first article related to this topic, we thought that may provide a starting point for readers regarding further studies.
In conclusion, based on the findings of our study showing the positive effects of sildenafil on nerve damage recovery and bone recovery, we suggest using sildenafil as a supportive clinical treatment of nerve damage. Future studies regarding the use of this molecule in nerve damage treatment in humans still need to be conducted.

Ethics Committee Approval: Ethics committee approval was received for this study from the ethics committee of İnönü University School of Medicine (No. 2012/A71).

\section{Informed Consent: N/A.}

Peer-review: Externally peer-reviewed.

Author contributions: Concept - M.F.K, H.P.; Design - M.F.K., H.P., M.F.C.; Supervision - M.F.K., L.E.; Resource - M.F.K., H.P., E.Ş., E.K., M.S.; Materials - M.F.K., H.P., M.S.; Data Collection and/or Processing - M.F.C., L.E., E.Ş., E.K.; Analysis and/or Interpretation - M.F.K., H.P.; Literature Search - M.F.C., L.E., M.S.; Writing - M.F.K., H.P.; Critical Reviews - M.F.K., H.P., E.Ş., E.K.

Acknowledgements: The authors are grateful to Dr. Mehmet Ali Erdoğan (Department of Anesthesia and Intensive Care Unit) and Dr. Yılmaz Çiğremiş (Department of Medical Biology and Genetics) for the excellent art work and their technical support.

Conflict of Interest: No conflict of interest was declared by the authors.

Financial Disclosure: The authors declared that this study has received no financial support.

\section{REFERENCES}

1. Avci G, Akan M, Yildirim S, Akoz T. Sinir onarimi ve greftleme. T Klin J Med Sci 2002;22:428-37.

2. Rummler L, Gupta R. Peripheral nerve repair: a Review. Curr Opin Orthop 2004;15:215-9. [CrossRef]

3. Erbayraktar S, Grasso G, Sfacteria A, Xie QW, Coleman T, Kreilgaard M, et al. Asialoerythropoietin is a nonerythropoietic cytokine with broad neuroprotective activity in vivo. $P$ Natl Acad Sci USA 2003;100:6741-6. [CrossRef]

4. Korkmaz HA, Maltepe F, Erbayraktar S, Yilmaz O, Guray M, Canda MS, et al. Antinociceptive and neurotoxicologic screening of chronic intrathecal administration of ketorolac tromethamine in the rat. Anesthesia Analg 2004;98:148-52. [CrossRef]

5. Seddon HJ, Medawar PB, Smith H. Rate of regeneration of peripheral nerves in man. J Physiol 1943;102:191-215. [CrossRef]

6. Varejao AS, Meek MF, Ferreira AJ, Patricio JA, Cabrita AM. Functional evaluation of peripheral nerve regeneration in the rat: walking track analysis. J Neurosci Methods 2001;108:1-9. [CrossRef] 
7. Das S, Maulik N, Das DK, Kadowitz PJ, Bivalacqua TJ. Cardioprotection with sildenafil, a selective inhibitor of cyclic 3',5'-monophosphate-specific phosphodiesterase 5. Drugs Exp Clin Res 2002;28:213-9.

8. Salloum F, Yin C, Xi L, Kukreja RC. Sildenafil induces delayed preconditioning through inducible nitric oxide synthasedependent pathway in mouse heart. Circ Res 2003;92:595-7. [CrossRef]

9. Bandera BC, Pham T, Hill-Pryor C, Bah-Sow M, Franco N, Prasad BM, et al. Role of Growth Factors in Improved Skin Flap Viability Caused by Phosphodiesterase-5 Inhibitor. Am Surg 2010;76:614-7.

10. Mulhall JP, Muller A, Donohue JF, Mullerad M, Kobylarz K, Paduch DA, et al. The functional and structural consequences of cavernous nerve injury are ameliorated by sildenafil citrate. J Sex Med 2008;5:1126-36. [CrossRef]

11. Yucel A, Aydogan MS, Parlakpinar H, Erdogan MA, Kurt A, Ucar M, et al. Effects of propofol and dexmedetomidine on motor coordination and analgesia: A comparative analysis. Int J Clin Pharmacol Ther 2012;50:678-82. [CrossRef]

12. Baptista AF, Gomes JR, Oliveira JT, Santos SM, VannierSantos MA, Martinez AM. A new approach to assess function after sciatic nerve lesion in the Mouse adaptation of the sciatic static index. J Neurosci Methods 2007;161:259-64. [CrossRef]

13. Ali Erdogan M, Polat A, Yucel A, Aydogan MS, Parlakpinar $\mathrm{H}$, Tekin S, et al. Effects of perineural administration of dexmedetomidine in combination with levobupivacaine in a rat sciatic nerve block. Curr Ther Res Clin Exp 2013;74:74-8. [CrossRef]

14. Arslan E, Milcan A, Unal S, Demirkan F, Polat A, Bagdatoglu $\mathrm{O}$, et al. The effects of carnitine on distally-burned dorsal skin flap: an experimental study in rats. Burns 2003;29:2217. [CrossRef]

15. Bagdatoglu C, Saray A, Surucu HS, Ozturk H, Tamer L. Effect of trapidil in ischemia/reperfusion injury of peripheral nerves. Neurosurgery 2002;51:212-9; discussion 219-20. [CrossRef]

16. Zochodne DW, Ho LT. Endoneurial microenvironment and acute nerve crush injury in the rat sciatic nerve. Brain Res 1990;535:43-8. [CrossRef]

17. Sunderland S. The anatomy and physiology of nerve injury. Muscle Nerve 1990;13:771-84. [CrossRef]

18. Seddon H. Three types of nerve injury. Brain 1943;66:23788. [CrossRef]

19. Al-Bishri A, Dahlin L, Sunzel B, Rozenquist J. Systemic betamethasone accelerates functional recovery after a crush injury to rat sciatic nerve. J Oral Maxillofac Surg 2005;63:9737. [CrossRef]

20. Ditor DS, John SM, Roy J, Marx JC, Kittmer C, Weaver LC. Effects of polyethylene glycol and magnesium sulfate administration on clinically relevant neurological out- comes after spinal cord injury in the rat. $J$ Neurosci Res 2007;85:1458-67. [CrossRef]

21. Le Prell CG, Hughes LF, Miller JM. Free radical scavengers vitamins $\mathrm{A}, \mathrm{C}$, and $\mathrm{E}$ plus magnesium reduce noise trauma. Free Radic Biol Med 2007;42:1454-63. [CrossRef]

22. Lee M, Doolabh VB, Mackinnon SE, Jost S. FK506 promotes functional recovery in crushed rat sciatic nerve. Muscle Nerve 2000;23:633-40. [CrossRef]

23. Subbanna PK, Prasanna CG, Gunale BK, Tyagi MG. Acetyl salicylic acid augments functional recovery following sciatic nerve crush in mice. J Brachial Plex Peripher Nerve Inj 2007;2:3.

24. Wilson AD, Hart A, Brannstrom T, Wiberg M, Terenghi G. Delayed acetyl-L-carnitine administration and its effect on sensory neuronal rescue after peripheral nerve injury. $J$ Plast Reconstr Aesthet Surg 2007;60:114-8. [CrossRef]

25. Gordon T, Sulaiman O, Boyd JG. Experimental strategies to promote functional recovery after peripheral nerve injuries. $J$ Peripher Nerv Syst 2003;8:236-50. [CrossRef]

26. Stoll G, Muller HW. Nerve injury, axonal degeneration and neural regeneration: basic insights. Brain Pathol 1999;9:31325. [CrossRef]

27. Gudemez E, Ozer K, Cunningham B, Siemionow K, Browne E, Siemionow M. Dehydroepiandrosterone as an enhancer of functional recovery following crush injury to rat sciatic nerve. Microsurgery 2002;22:234-41. [CrossRef]

28. Oliveira EF, Mazzer N, Barbieri CH, Selli M. Correlation between functional index and morphometry to evaluate recovery of the rat sciatic nerve following crush injury: Experimental study. $J$ Reconstr Microsurg 2001;17:69-75. [CrossRef]

29. Rempel D, Dahlin L, Lundborg G. Pathophysiology of nerve compression syndromes: Response of peripheral nerves to loading. J Bone Joint Surg Am 1999;81A:1600-10.

30. Johnson EO, Zoubos AB, Soucacos PN. Regeneration and repair of peripheral nerves. Injury 2005;36:S24-9. [CrossRef]

31. Galtrey CM, Fawcett GJW. Characterization of tests of functional recovery after median and ulnar nerve injury and repair in the rat forelimb. J Peripher Nerv Syst 2007;12:11-27. [CrossRef]

32. Novak CB, Mackinnon SE. Nerve injury in repetitive motion disorders. Clin Orthop Relat Res 1998;10-20. [CrossRef]

33. Zuo YX, Perkins NM, Tracey DJ, Geczy CL. Inflammation and hyperalgesia induced by nerve injury in the rat: a key role of mast cells. Pain 2003;105:467-79. [CrossRef]

34. Yang J, Li XH, Al-Lamki RS,Wu C, Weiss A, Berk J, et al. Sildenafil Potentiates Bone Morphogenetic Protein Signaling in Pulmonary Arterial Smooth Muscle Cells and in Experimental Pulmonary Hypertension. Arterioscl Throm Vas 2013;33:34-42. [CrossRef]

35. Yaman F, Atilgan S, Gunes N, Agacayak S, Günay A, Ucan $\mathrm{MC}$, et al. Phosphodiesterase-5 inhibitors may facilitate bone defect recovery. Eur Rev Med Pharmacol Sci 2011;15:13015. 
36. Histing T, Marciniak K, Scheuer C, Garcia P, Holstein JH, Klein $\mathrm{M}$, et al. Sildenafil Accelerates Fracture Healing in Mice. J Orthop Res 2011;29:867-73. [CrossRef]

37. Sun L, Pan JP, Peng YZ, Wu Y, Li J, Liu X, et al. Anabolic steroids reduce spinal cord injury-related bone loss in rats associated with increased Wnt signaling. J Spinal Cord Med 2013;36:616-22. [CrossRef]

38. Jiang SD, Jiang LS, Dai LY. Spinal cord injury causes more damage to bone mass, bone structure, biomechanical proper- ties and bone metabolism than sciatic neurectomy in young rats. Osteoporos Int 2006;17:1552-61. [CrossRef]

39. Suyama H, Moriwaki K, Niida S, Maehara Y, Kawamoto M, Yuge O. Osteoporosis following chronic constriction injury of sciatic nerve in rats. J Bone Miner Metab 2002;20:91-7. [CrossRef]

40. Cardozo CP, Qin WP, Peng YZ, Liu X, Wu Y, Pan J, et al. Nandrolone slows hindlimb bone loss in a rat model of bone loss due to denervation. Ann Ny Acad Sci 2010;1192:303-6.[CrossRef] 